BMJ Open

Sport \&

Exercise

Medicine

\title{
Cardiac systolic regional function and synchrony in endurance trained and untrained females
}

\author{
Kristofer Hedman, ${ }^{1}$ Éva Tamás, ${ }^{2}$ Niclas Bjarnegård, ${ }^{3}$ Lars Brudin, ${ }^{4}$ Eva Nylander ${ }^{1}$
}

To cite: Hedman K, Tamás É, Bjarnegård N, et al. Cardiac systolic regional function and synchrony in endurance trained and untrained females. BMJ Open Sport Exerc Med 2015;0:e000015. doi:10.1136/bmjsem-2015000015

- Prepublication history and additional material is available. To view please visit the journal (http://dx.doi.org/ 10.1136/bmjsem-2015000015)

Accepted 29 July 2015

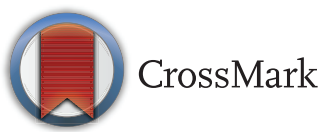

${ }^{1}$ Department of Clinical Physiology and Department of Medical and Health Sciences, Linköping University, Linköping, Sweden

${ }^{2}$ Department of Cardiothoracic and Vascular Surgery and Department of Medical and Health Sciences, Linköping University,

Linköping, Sweden

${ }^{3}$ Department of Medical and Health Sciences, Linköping University, Linköping; Department of Clinical Physiology, County Hospital Ryhov, Jönköping, Sweden ${ }^{4}$ Department of Medical and Health Sciences, Linköping University, Linköping and Department of Clinical Physiology, County Hospital, Kalmar, Sweden

Correspondence to Dr Kristofer Hedman; kristofer.hedman@liu.se

\section{ABSTRACT}

Background: Most studies on cardiac function in athletes describe overall heart function in predominately male participants. We aimed to compare segmental, regional and overall myocardial function and synchrony in female endurance athletes $(\mathrm{ATH})$ and in age-matched sedentary females (CON).

Methods: In 46 ATH and 48 CON, echocardiography was used to measure peak longitudinal systolic strain and myocardial velocities in 12 left ventricular (LV) and 2 right ventricular (RV) segments. Regional and overall systolic function were calculated together with four indices of dyssynchrony.

Results: There were no differences in regional or overall LV systolic function between groups, or in any of the four dyssynchrony indices. Peak systolic velocity $\left(s^{\prime}\right)$ was higher in the RV of ATH than in CON $(9.7 \pm 1.5$ vs $8.7 \pm 1.5 \mathrm{~cm} / \mathrm{s}, \mathrm{p}=0.004)$, but not after indexing by cardiac length $(p=0.331)$. Strain was similar in ATH and CON in 8 of 12 LV myocardial segments. In septum and anteroseptum, basal and mid-ventricular $\mathrm{s}^{\prime}$ was $6-7 \%$ and $17-19 \%$ higher in ATH than in CON $(p<0.05)$, respectively, while $s^{\prime}$ was $12 \%$ higher in CON in the basal LV lateral wall $(p=0.013)$. After indexing by cardiac length, $s^{\prime}$ was only higher in $\mathrm{ATH}$ in the mid-ventricular septum $(p=0.041)$.

Conclusions: We found differences between trained and untrained females in segmental systolic myocardial function, but not in global measures of systolic function, including cardiac synchrony. These findings give new insights into cardiac adaptation to endurance training and could also be of use for sports cardiologists evaluating female athletes.

\section{INTRODUCTION}

Numerous studies have provided support for cardiac dimensional adaptations in females engaging in endurance training. ${ }^{1}{ }^{2}$ Typically, there is an increase in left ventricular (LV) cavity dimension together with a slightly increased LV wall thickness, in parallel with right ventricular (RV) and atrial enlargement. ${ }^{1-3}$

While meta-analyses have found traditional measures of LV global systolic function at rest to be similar in athletes and controls, ${ }^{2}{ }^{45}$ evidence is not conclusive from studies utilising

\section{What are the new findings?}

- Endurance trained and untrained females had similar overall and regional cardiac function.

- There were differences in Iongitudinal systolic function in several myocardial segments between trained and untrained females.

- Indexing measures of longitudinal tissue velocities by cardiac length eradicated or altered a majority of statistical differences.

- There was no difference in systolic interventricular or intraventricular synchrony between endurance trained and untrained females.

tissue Doppler imaging (TDI) or speckle tracking to measure global LV or RV systolic function. $^{6-9}$ This could in part result from a variety of myocardial segments being used for calculating global measures. Hence, investigating and presenting segmental myocardial function could provide additional insight into cardiac adaptation to chronic exercise. To our knowledge, no previous study compares segmental myocardial function or global LV strain in trained and untrained females.

Moreover, the synchrony in contraction between myocardial segments is of importance for overall systolic function. Lack of synchrony, that is, dyssynchrony, has been shown in patients with hypertrophic cardiomyopathy compared with power athletes. ${ }^{10}$ Studies of synchrony in endurance athletes are surprisingly few. While one study found increased dyssynchrony in less experienced male longdistance runners compared with experienced runners before a $30 \mathrm{~km}$ race, ${ }^{11}$ two studies report a similar degree of dyssynchrony in healthy sedentary participants compared with different athletic samples. ${ }^{12}{ }^{13}$ Interestingly, there are reports of higher dyssynchrony indices in healthy females than in males, ${ }^{14} 15$ but it remains to be elucidated whether these indices are different between trained and untrained females.

We hypothesised that sedentary and endurance trained females would present a similar 
degree of dyssynchrony, and that differences in segmental systolic function might exist. Thus, the purposes of the current study were (1) to compare the degree of cardiac dyssynchrony in female endurance athletes and in agematched sedentary females, as well as (2) to evaluate and compare segmental myocardial longitudinal systolic function in the same groups.

\section{METHODS}

Subjects

Forty-six female athletes (ATH) under 26 years of age were recruited, all competing at a national level in orienteering $(\mathrm{n}=17)$, mid-distance or long-distance running $(n=6)$, triathlon $(n=5)$, canoeing $(n=5)$, biathlon $(n=4)$, cycling $(n=3)$, swimming $(n=3)$ or team handball $(n=3)$. On average, the ATH had been competing for $6 \pm 2$ years $($ mean $\pm S D)$ and trained $13 \pm 5 \mathrm{~h} /$ week. Forty-eight female students of similar age, not engaged in regular endurance or resistance training in recent years, were recruited as controls $(\mathrm{CON})$. Of these, $30 \mathrm{CON}$ described themselves as 'inactive' and 18 as 'normally active'. All participants were screened for cardiovascular disease, including a resting ECG, and underwent maximal bicycle ergometer testing. Details of inclusion procedure and exercise testing together with data on cardiac dimensions in these participants have previously been published. ${ }^{3}$ Informed consent was obtained from all participants. The study was approved by the regional ethical review board in Linköping, Sweden.

\section{Echocardiography}

Echocardiography was performed by experienced echocardiographers in accordance with current recommendations $;{ }^{16}$ our protocol for standard echocardiographic measurements has been previously described in detail. ${ }^{3}$ In the current study, colour TDI was used to measure peak systolic velocity off-line $\left(\mathrm{s}^{\prime}, \mathrm{cm} / \mathrm{s}\right)$ from standard four-chamber, three-chamber and two-chamber apical views, with a frame rate of $89-184$ frames/s. A $6 \times 6 \mathrm{~mm}$ round sample volume was placed in six basal and six mid-ventricular segments in the LV (at septal, anteroseptal, anterior, lateral, posterolateral and posterior walls), and in the basal and mid-ventricular RV free wall. Measurements were averaged over two to three beats, with markers of aortic valve opening and closing superimposed on TDI-images to ensure measurements in ejection phase only. The time from onset of the QRS complex to $\mathrm{s}^{\prime}\left(\mathrm{T}_{\mathrm{S}}\right)$ was determined in all segments (see online supplementary file 1 , where TDI and speckle tracking is visualised).

The $12 \mathrm{LV}$ segments were further investigated with speckle tracking from two-dimensional (2D) images with a frame rate $>40$ frames $/ \mathrm{s}$ in the same three apical views, and mid-wall peak systolic longitudinal strain (\%) during ejection phase was determined. The myocardium was automatically outlined with a region of interest, which, if necessary, was corrected manually with regard to width and localisation to exclude the pericardium. The software automatically analysed the quality of speckle tracking in each segment; segments with poor tracking were excluded from further measurements.

Regional LV function was determined by calculating the arithmetic means of the six basal and six midventricular LV segments, respectively, together with overall LV function for all 12 segments studied (LV-12). Only measurements from those individuals where all six basal or mid-ventricular segments were measurable were included in calculations of regional and overall function. As cardiac length previously has been found to influence measures of myocardial longitudinal function, ${ }^{3}{ }^{9}$ peak systolic velocities were indexed by LV length.

\section{Dyssynchrony indices}

Four established systolic dyssynchrony indexes were calculated: (1) S-L-delay, the largest difference in $T_{S}$ between basal septal-to-lateral and posterior-to-anterior $\mathrm{LV}$ walls; ${ }^{17}$ (2) Max-LV-delay, the largest difference in $\mathrm{T}_{\mathrm{S}}$ between any 2 out of $12 \mathrm{LV}$ segments; ${ }^{18}$ (3) $\mathrm{T}_{\mathrm{S}} \mathrm{SD}$, the $\mathrm{SD}$ of $\mathrm{T}_{\mathrm{S}}$ in all $12 \mathrm{LV}$ segments ${ }^{19}$ and (4) RV-LV-delay, the difference in $\mathrm{T}_{\mathrm{S}}$ between basal $\mathrm{RV}$ free wall and $\mathrm{LV}$ lateral wall. ${ }^{19}$ In addition, $T_{S}$ was indexed by one RR interval and was expressed as a percentage of total cardiac cycle length $\left(\mathrm{T}_{\mathrm{S}^{-}} \%\right)$. The dyssynchrony measurements were compared to cut-off values previously suggested for predicting outcomes following cardiac resynchronisation therapy. ${ }^{17-19}$

\section{Statistical analysis}

Normally distributed continuous variables were expressed as mean $\pm \mathrm{SD}$, between-group differences were determined with Student $t$ test and paired $t$ tests were used for within-group analysis. Non-normally distributed variables were presented as median with 25 th and 75 th percentiles and between-group differences were determined with the Mann-Whitney test. The Fisher's exact test or the $\chi^{2}$ test was used for comparing categorical variables. A significance level of $p \leq 0.05$ was chosen since data are mainly descriptive and not inferential. IBM SPSS Statistics V.22 was used for all data analysis (IBM Software, 2013, Armonk, New York, USA).

In 16 randomly selected participants, the intratester and intertester variability of off-line analysis was explored for six strain, eight $\mathrm{s}^{\prime}$ and eight $\mathrm{T}_{\mathrm{S}}$ measurements. Intratester variability was tested at least 2 weeks following the first measurements, and intertester variability was tested against a second experienced investigator. The coefficient of variation (\% COV) was calculated as $\left(\sqrt{ }\left(\sum d_{i}^{2} / 2 n\right) /(\right.$ overall means $\left.)\right)$, where $d_{i}$ is the difference between the ith paired measurement and $n$ the number of differences. ${ }^{20}$ In addition, the single measure intraclass correlation coefficient was calculated for interobserver and intraobserver variability in an absolute agreement two-way mixed model. 
Table 1 Reproducibility data

\begin{tabular}{lccccc}
\hline & \multicolumn{2}{c}{ Intertester } & & \multicolumn{2}{c}{ Intratester } \\
\cline { 2 - 3 } \cline { 6 - 6 } & COV (\%) & ICC & & COV (\%) & ICC \\
\hline Velocity $\left(\mathrm{s}^{\prime}\right)$ & 11.5 & 0.76 & 11.5 & 0.71 \\
Strain & 8.2 & 0.70 & 6.4 & 0.85 \\
$\mathrm{~T}_{\mathrm{S}}$ & 11.7 & 0.58 & 11.6 & 0.62
\end{tabular}

For details of calculations see Methods section.

COV, covariance in per cent; ICC, intraclass correlation coefficient; $\mathrm{T}_{\mathrm{S}}$, time to $\mathrm{s}^{\prime}$.

\section{RESULTS}

\section{Data quality and reproducibility}

In total, image quality permitted measurements of systolic peak velocities in $1283(98 \%)$ myocardial segments and strain in 1048 (93\%) segments. Reproducibility data are presented in table 1 .

\section{Subject characteristics and ECG data}

Athletes and CON were of similar age (both $21 \pm 2$ years, $\mathrm{p}=0.743)$ and had similar body mass index $(22 \pm 2$ and 21 $\pm 2 \mathrm{~kg} / \mathrm{m}^{2}$, respectively, $\left.\mathrm{p}=0.219\right)$. Athletes were heavier $(61 \pm 6$ vs $58 \pm 6 \mathrm{~kg}, \mathrm{p}=0.009)$ and had larger body surface area $\left(1.68 \pm 0.10\right.$ vs $\left.1.63 \pm 0.09 \mathrm{~m}^{2}, \mathrm{p}=0.008\right)$ than $\mathrm{CON}$. Peak oxygen uptake was $52 \pm 5 \mathrm{~mL} / \mathrm{kg} / \mathrm{min}$ in ATH and $39 \pm 5 \mathrm{~mL} / \mathrm{kg} / \mathrm{min}$ in CON $(\mathrm{p}<0.001)$. Systolic and diastolic blood pressures at rest were similar and within normal limits for both groups. All measured cardiac dimensions were larger in ATH and have been described in detail previously. ${ }^{3}$ Median LV ejection fraction (LVEF) was $60 \%(57-62 \%)$ and $57 \%(54-61 \%)$ in ATH and CON, respectively.

ECG data at rest revealed a slightly longer mean QRS duration in ATH than in CON, with no other statistically significant difference between groups (table 2). No participant had a history of symptoms during exercise and all ECGs were categorised as normal by an experienced clinical physiologist.

\section{Systolic timing and synchrony}

While $\mathrm{T}_{\mathrm{S}}$ was longer in ATH than in CON in three midventricular and one basal segment (figure 1), when adjusting for the lower heart rate in ATH than in CON (mean RR interval $1156 \pm 183$ vs $878 \pm 130 \mathrm{~ms}, \mathrm{p}<0.001$ ), $\mathrm{T}_{\mathrm{S}}-\%$ was longer in CON in all 14 myocardial segments $($ all $\mathrm{p}<0.05)$.

Absolute $\mathrm{T}_{\mathrm{S}}$ in the basal LV was $160 \pm 19 \mathrm{~ms}$ in ATH and $153 \pm 18 \mathrm{~ms}$ in CON ( $\mathrm{p}=0.085)$, which corresponded to $14 \%$ and $18 \%$ of total cardiac cycle length in ATH and CON, respectively $(\mathrm{p}<0.001)$. Absolute (and relative) mid-ventricular $\mathrm{T}_{\mathrm{S}}$ was $158 \pm 18 \quad(14 \%)$ and 150 $\pm 17 \mathrm{~ms}(17 \%)$ in ATH and CON, with $\mathrm{p}=0.032$ for absolute and $\mathrm{p}<0.001$ for relative measures. The corresponding values for $L V-12-T_{S}$ were $159 \pm 17$ and $150 \pm 17 \mathrm{~ms}$ ( $p=0.023$ ), corresponding to $14 \%$ and $17 \%$ of cardiac cycle length, respectively $(\mathrm{p}<0.001)$.

In within-group comparison, there was no statistically significant difference between average basal and midventricular $T_{S}$ in either ventricle.

No difference in any index of dyssynchrony was seen between groups (table 3). A majority of participants in both groups displayed dyssynchrony values clearly above previously suggested cut-off values for cardiac resynchronisation therapy (figure 2). For all participants, 95th percentiles (with maximum values) for the dyssynchrony indices were as follows: S-L-delay $120 \mathrm{~ms}$ (150 ms), Max-LV-delay $150 \mathrm{~ms}$ (160 ms), $\mathrm{T}_{\mathrm{S}}$-SD 54 (59) and RV-LV-delay $140 \mathrm{~ms}$ (160 ms).

Table 2 ECG data at rest

\begin{tabular}{|c|c|c|c|c|c|}
\hline & \multicolumn{2}{|c|}{ ATH } & \multicolumn{2}{|c|}{ CON } & \multirow[b]{2}{*}{ p Value } \\
\hline & $n$ & Range & $\bar{n}$ & Range & \\
\hline \multicolumn{6}{|l|}{$P Q$ interval } \\
\hline$<120 \mathrm{~ms}$ & 1 & (108 ms) & 1 & (108 ms) & 1.0 \\
\hline 120 to $220 \mathrm{~ms}$ & 45 & (120 to $210 \mathrm{~ms}$ ) & 46 & (120 to $220 \mathrm{~ms}$ ) & \\
\hline Mean & \multicolumn{2}{|c|}{$154 \pm 22 \mathrm{~ms}$} & \multicolumn{2}{|c|}{$153 \pm 24 \mathrm{~ms}$} & 0.842 \\
\hline \multicolumn{6}{|l|}{ QRS duration } \\
\hline$\leq 100 \mathrm{~ms}$ & 41 & (76 to $100 \mathrm{~ms}$ ) & 43 & (70 to $100 \mathrm{~ms}$ ) & 0.740 \\
\hline$>100,<120 \mathrm{~ms}$ & 5 & (104 to $112 \mathrm{~ms}$ ) & 4 & (102 to $112 \mathrm{~ms}$ ) & \\
\hline Mean & \multicolumn{2}{|c|}{$92 \pm 8 \mathrm{~ms}$} & \multicolumn{2}{|c|}{$88 \pm 9 \mathrm{~ms}$} & 0.019 \\
\hline \multicolumn{6}{|l|}{ QRS axis } \\
\hline$<-30^{\circ}$ & 0 & - & 1 & $-39^{\circ}$ & 0.131 \\
\hline$-30^{\circ}$ to $90^{\circ}$ & 39 & $\left(-8^{\circ}\right.$ to $\left.90^{\circ}\right)$ & 44 & $\left(2^{\circ}\right.$ to $\left.90^{\circ}\right)$ & \\
\hline$>90^{\circ}$ & 7 & $\left(91^{\circ}\right.$ to $\left.106^{\circ}\right)$ & 2 & $\left(96^{\circ}\right.$ to $\left.103^{\circ}\right)$ & \\
\hline Mean & \multicolumn{2}{|c|}{$70^{\circ} \pm 24$} & \multicolumn{2}{|c|}{$66^{\circ} \pm 27$} & 0.377 \\
\hline \multicolumn{6}{|l|}{ QTc interval } \\
\hline$<460 \mathrm{~ms}$ & 43 & (376 to $457 \mathrm{~ms}$ ) & 47 & (383 to $456 \mathrm{~ms}$ ) & 0.117 \\
\hline$\geq 460 \mathrm{~ms}$ & 3 & (463 to $499 \mathrm{~ms}$ ) & 0 & - & \\
\hline Mean & \multicolumn{2}{|c|}{$428 \pm 26 \mathrm{~ms}$} & \multicolumn{2}{|c|}{$428 \pm 18 \mathrm{~ms}$} & 0.990 \\
\hline
\end{tabular}

*Statistical significance tested with Student $t$ test for means, Fisher's exact test for two categorical variables and $\chi^{2}$ for three categorical variables. Data presented as number of participants $(n)$ with range of measurements, as well as group means with SDs. 
A
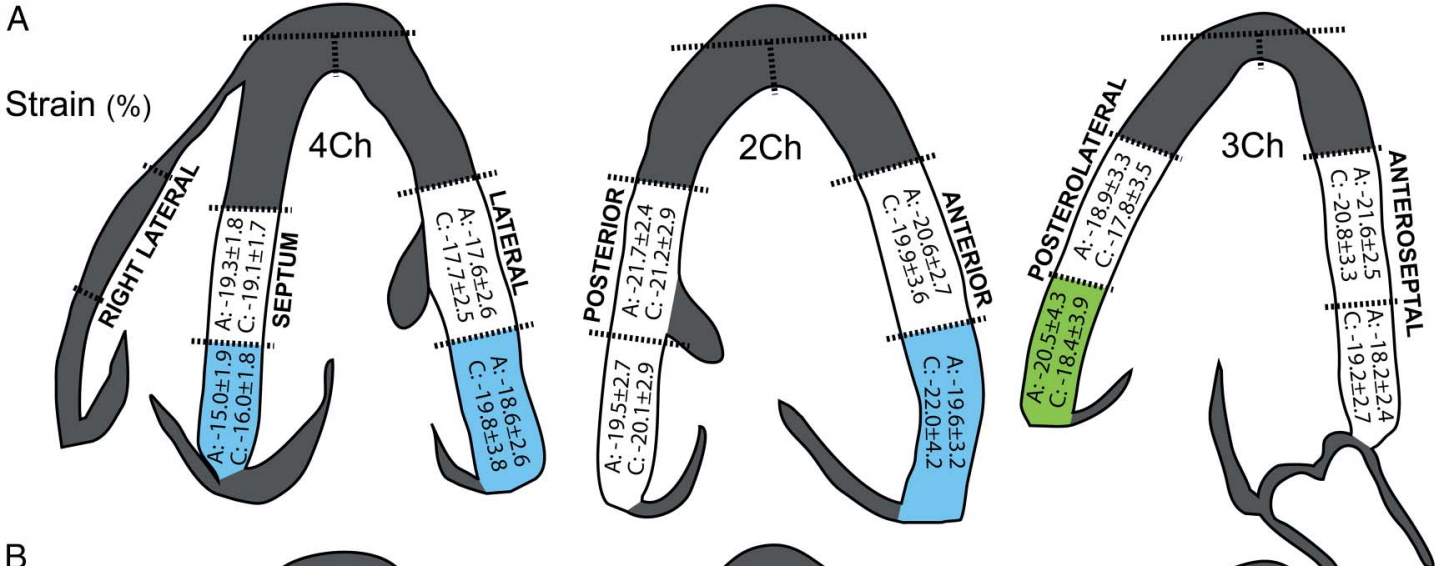

B $\left(\mathrm{s}^{\prime}, \mathrm{cm} \cdot \mathrm{s}^{-1}\right)$
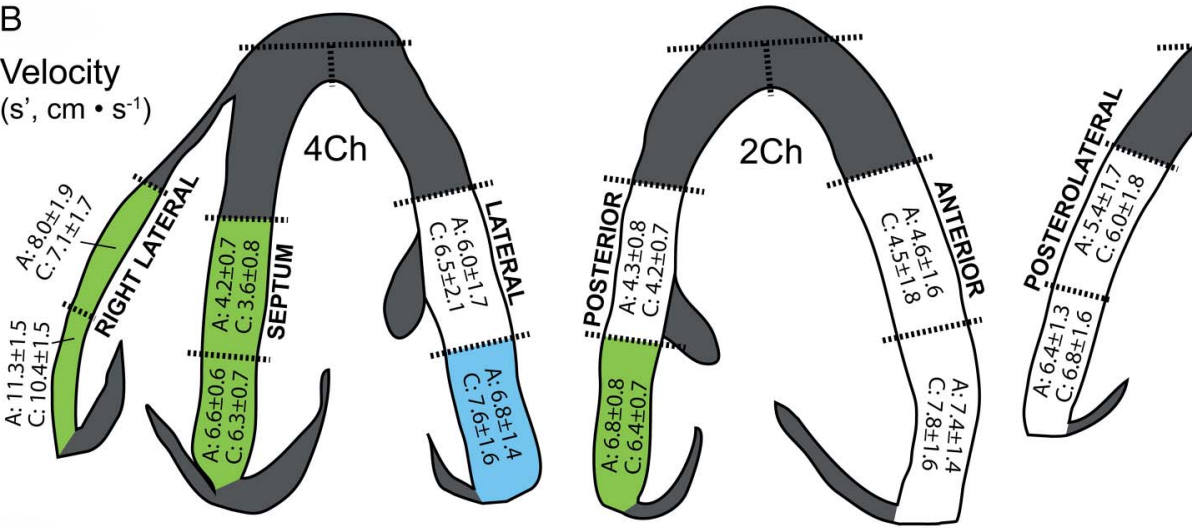

。
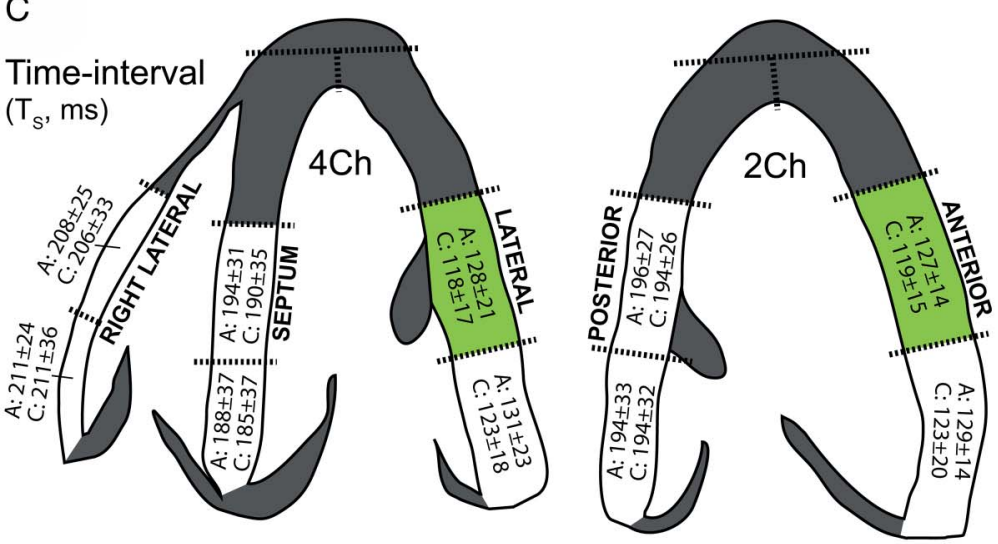

$=$ mean higher in athletes $(A)(p \leq 0.05)$

$=$ mean higher in controls $(C)(p \leq 0.05)$

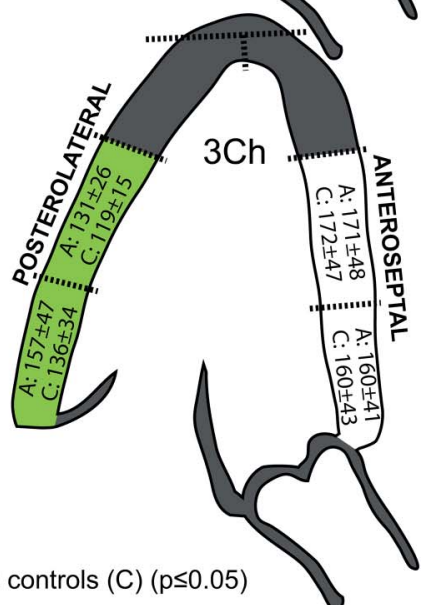

Figure 1 Segmental peak systolic strain (A), peak systolic velocity (B) and time to peak systolic velocity (C) from three apical views, mean $\pm S D$. In segments with a statistically significant difference $(p \leq 0.05)$ between groups, the colour green denotes higher mean value in athletes and blue denotes higher mean value in controls. A, athletes; $\mathrm{C}$, controls; $4 \mathrm{Ch}$, four-chamber view; $2 \mathrm{Ch}$, two-chamber view; $3 \mathrm{Ch}$, three-chamber long-axis view.

\section{Longitudinal systolic myocardial function}

Peak systolic velocity and strain for separate myocardial segments are presented in figure 1.

Mean $\mathrm{s}^{\prime}$ in the basal LV was higher than at the midventricular level in both ATH and CON (both $\mathrm{p}<0.001$ ). Mean mid-ventricular strain was larger than mean basal strain in ATH $(\mathrm{p}<0.001)$ while similar in CON $(\mathrm{p}=0.511)$. LV-12-s' was lower than RV-s' in both ATH and CON (both $\mathrm{p}<0.001$ ).
There were no between-group differences in LV regional (ie, basal or mid-ventricular) or in overall (LV-12) systolic function measured as $\mathrm{s}^{\prime}$ or strain (table 4). Mean peak systolic velocity in the RV free wall $\left(\mathrm{RV}-\mathrm{s}^{\prime}\right)$ was higher in ATH than in CON $(9.7 \pm 1.5$ vs $8.7 \pm 1.5 \mathrm{~cm} / \mathrm{s}, \mathrm{p}=0.004)$.

When accounting for the increased LV length in ATH $(8.5 \pm 0.5$ vs $7.9 \pm 0.5 \mathrm{~cm}$, respectively, $\mathrm{p}<0.001)$, indexed $\mathrm{s}^{\prime}$ was only higher in ATH in the mid-ventricular septal wall ( $p=0.041$, see online supplementary file 2 ). 
Table 3 Dyssynchrony indexes in athletes and controls

\begin{tabular}{|c|c|c|c|c|c|c|c|c|c|}
\hline & \multicolumn{4}{|l|}{ Athletes } & \multicolumn{4}{|l|}{ Controls } & \multirow[b]{2}{*}{ p Value } \\
\hline & Median & 25th & 75th & 95th & Median & 25th & 75th & 95th & \\
\hline S-L-delay (ms) & 70 & 60 & 100 & 120 & 85 & 70 & 100 & 120 & 0.159 \\
\hline Max-LV-delay (ms) & 105 & 90 & 120 & 160 & 110 & 100 & 128 & 146 & 0.574 \\
\hline $\mathrm{T}_{\mathrm{S}}-\mathrm{SD}$ & 39 & 31 & 47 & 55 & 41 & 35 & 48 & 55 & 0.324 \\
\hline RV-LV-delay (ms) & 80 & 70 & 100 & 127 & 85 & 60 & 100 & 156 & 0.775 \\
\hline
\end{tabular}

Data presented as median with 25th, 75th and 95th percentiles. S-L-delay, largest difference in $T_{S}$ between basal septum and LV lateral wall and LV anterior and posterior wall; Max-LV-delay, largest difference in $T_{S}$ between all 12 LV segments; $T_{S}-S D, S D$ of $T_{S}$ in all 12 LV segments; RV-LV-delay, difference in $T_{S}$ between basal RV free wall and LV lateral wall.

$L V$, left ventricular; RV, right ventricular; $T_{S}$, time from onset of the QRS complex to $s^{\prime}$.

Indexing RV-s' by LV length eradicated statistical significance $(\mathrm{p}=0.331)$, while indexing $\mathrm{LV}-\mathrm{s}^{\prime}$ revealed higher indexed $s^{\prime}$ in CON than ATH in the basal LV $(\mathrm{p}=0.002)$ and in overall LV-12-s' $(\mathrm{p}=0.019)$, but not at the mid-ventricular level $(\mathrm{p}=0.187)$.
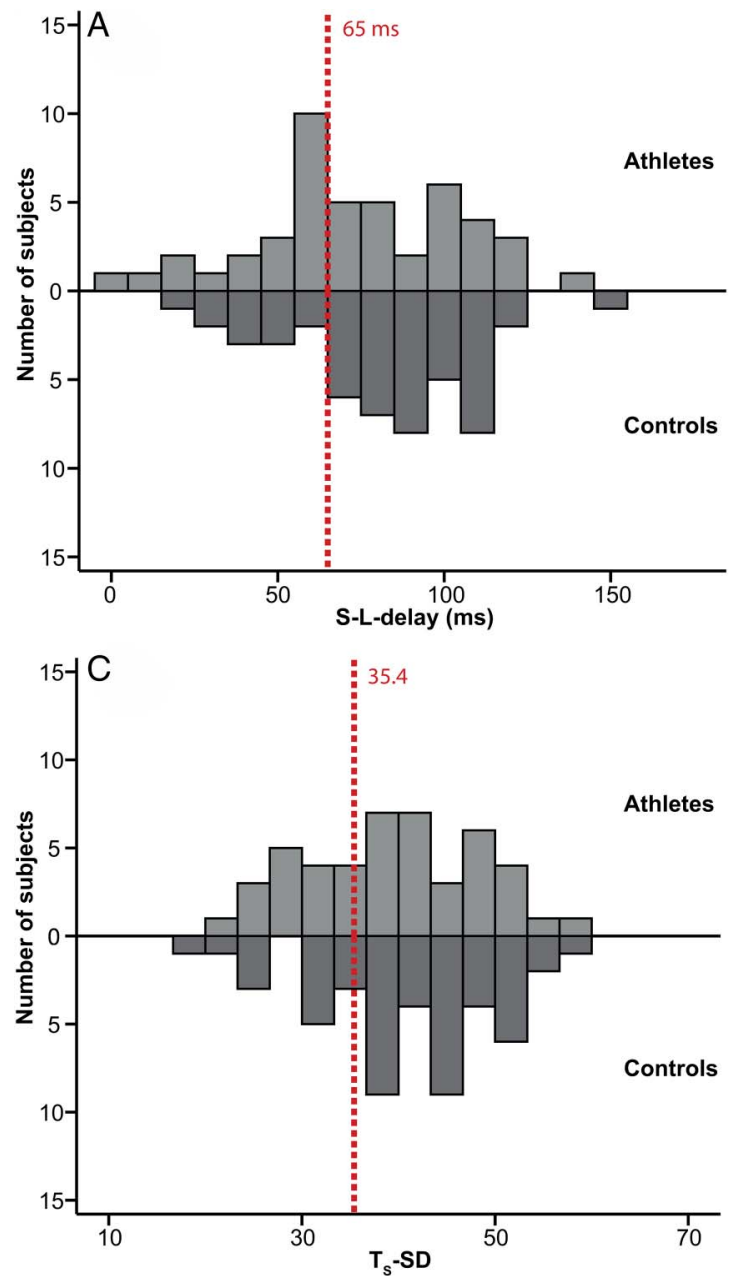

\section{DISCUSSION}

The main finding of this study was a difference in segmental systolic myocardial function between trained and untrained females, despite similar overall and regional cardiac function, as well as a similar degree of
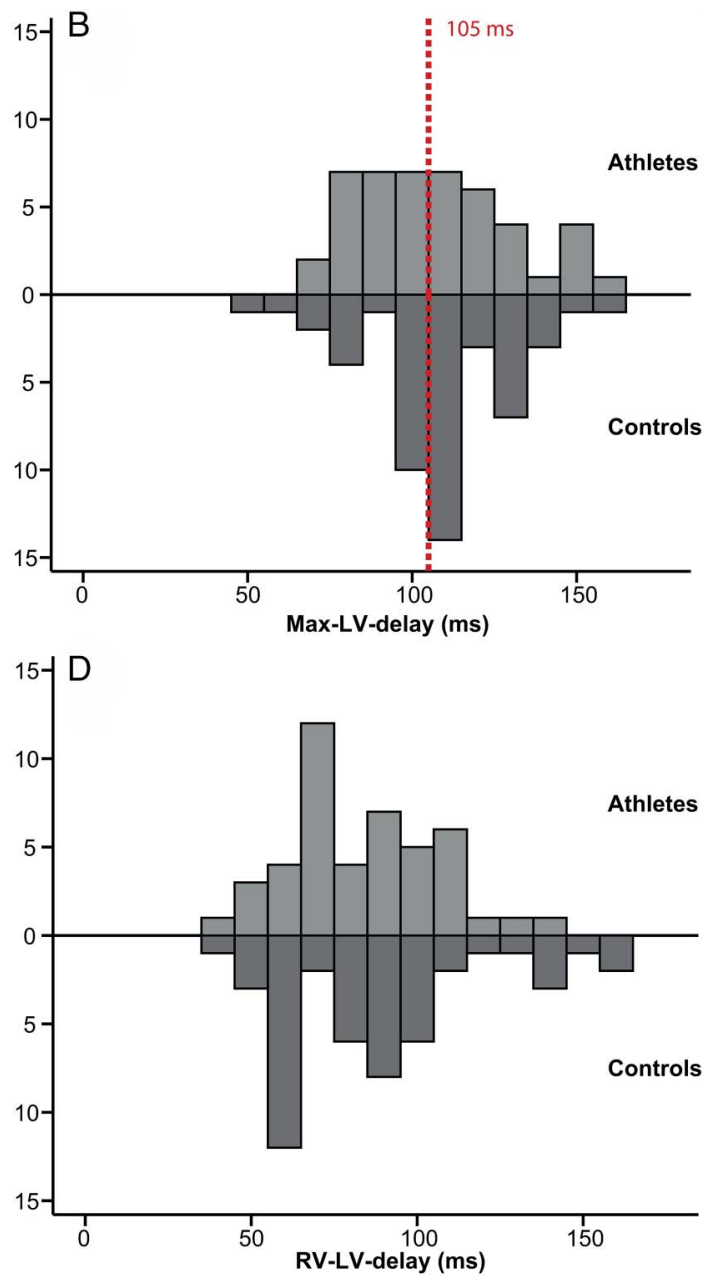

Figure 2 Histograms presenting distribution of dyssynchrony indices in athletes and controls. For details regarding calculations of dyssynchrony indices, see Methods section. Red lines and numbers represent suggested cut-off values in heart failure patients. (A) S-L-delay; (B) Max-LV-delay; (C) TS-SD and (D) RV-LV-delay. One athlete presenting a negative RV-LV-delay $(-60 \mathrm{~ms})$ was treated as an outlier and is not included in this histogram. S-L-delay, largest difference in $T_{S}$ between basal septum and LV lateral wall, and LV anterior and posterior wall; Max-LV-delay, largest difference in $T_{S}$ between all 12 LV segments; $T_{S}$-SD, SD of $T_{S}$ in all 12 LV segments; RV-LV-delay, difference in $T_{S}$ between basal RV free wall and LV lateral wall; LV, left ventricular; $\mathrm{RV}$, right ventricular; $\mathrm{T}_{\mathrm{S}}$, time from onset of the QRS complex to $\mathrm{s}^{\prime}$. 
Table 4 Arithmetic means of LV systolic longitudinal peak velocity and strain

\begin{tabular}{|c|c|c|c|c|c|c|}
\hline & \multicolumn{2}{|l|}{ Basal LV* } & \multicolumn{2}{|c|}{ Mid-ventricular LV } & \multicolumn{2}{|l|}{ LV-12 } \\
\hline & $\begin{array}{l}\mathbf{s}^{\prime} \\
(\mathrm{cm} / \mathrm{s})\end{array}$ & $\begin{array}{l}\text { Strain } \\
(\%)\end{array}$ & $\begin{array}{l}\mathbf{s}^{\prime} \\
(\mathrm{cm} / \mathrm{s})\end{array}$ & $\begin{array}{l}\text { Strain } \\
(\%)\end{array}$ & $\begin{array}{l}\mathbf{s}^{\prime} \\
(\mathrm{cm} / \mathrm{s})\end{array}$ & $\begin{array}{l}\text { Strain } \\
(\%)\end{array}$ \\
\hline ATH & $6.7 \pm 0.7(46)$ & $-18.6 \pm 1.8(45)$ & $4.7 \pm 0.7(45)$ & $-20.0 \pm 1.6(45)$ & $5.7 \pm 0.6(45)$ & $-19.3 \pm 1.5(45)$ \\
\hline $\mathrm{CON}$ & $6.8 \pm 0.7(44)$ & $-19.3 \pm 1.9(37)$ & $4.7 \pm 0.8(36)$ & $-19.5 \pm 1.6(37)$ & $5.7 \pm 0.7(36)$ & $-19.4 \pm 1.6(36)$ \\
\hline p Value & 0.871 & 0.072 & 0.771 & 0.180 & 0.905 & 0.773 \\
\hline
\end{tabular}

dyssynchrony. However, indexing peak systolic velocities by the increased cardiac length of ATH eradicated statistical significance in all segments but one.

\section{Systolic timing and synchrony}

The normal heart is not perfectly synchronised, owing to a non-uniformity in ventricular geometry, architecture and fibre orientation, in combination with regional differences in electrical activation and activation-contraction coupling. ${ }^{21}$ Although increased dyssynchrony has been found in patients with pathological hypertrophy (ie, hypertrophic cardiomyopathy), ${ }^{10}$ little is known regarding the synchrony in endurance trained athletes with physiological hypertrophy compared with sedentary participants.

We found similar interventricular and intraventricular synchrony in trained and untrained females implicating that chronic endurance exercise in females, albeit associated with substantial cardiac remodelling, does not impose systolic mechanical dyssynchrony compared with untrained females. Thus, dyssynchrony above what is generally reported in females ${ }^{14}{ }^{22}$ does not seem to be a physiological adaptation to endurance exercise and should merit further investigation if present in an athlete, bearing in mind, for example, previous findings of increased dyssynchrony in hypertrophic cardiomyopathy. ${ }^{10}$ Furthermore, we showed that available cut-off values used in heart failure patients ${ }^{17-19}$ cannot be applied in determining an abnormal level of dyssynchrony in endurance athletes, which is in line with previous studies on healthy participants. $^{1415}$

Less than a handful of studies have compared cardiac synchrony in athletes and sedentary participants. Two studies have used 3D echocardiography to calculate a dyssynchrony index normalised by cardiac cycle length (SDI \%). ${ }^{12}{ }^{13}$ No difference was observed between their cohorts of healthy participants versus male soccer players $^{12}$ and Olympic athletes of different sports, respectively. ${ }^{13}$ In the latter study by Caselli $e t a l,{ }^{13}$ a tendency $(\mathrm{p}=0.058)$ towards a lower degree of SDI \% in athletes was reported, which could be a result of indexing by longer cardiac cycles (ie, lower heart rate) in athletes. Finally, using similar dyssynchrony indices as in the current study, Sahlén et $a l^{11}$ reported larger S-L-delay in 20 male first-time runners (age $48 \pm 8$ years) compared with 23 repeat runners (age $46 \pm 6$ years) prior to a $30 \mathrm{~km}$ race. Interestingly, they found that after the race, dyssynchrony increased significantly only in first-time runners and was correlated to an increase in biochemical markers of cardiac damage. Altogether, the few and diverse available studies call for further research.

\section{Overall and regional LV and RV systolic function}

Our results of a preserved overall LV systolic function together with enlarged cardiac dimensions in trained females depict the physiological hypertrophy seen with endurance training. There is a multitude of reports on normal LVEF at rest in trained participants. ${ }^{2} 45$ In males, average basal ${\mathrm{LV}-\mathrm{s}^{\prime}}^{\prime}$ is typically reported to be similar in endurance athletes and sedentary controls, ${ }^{9} 2324$ while global peak systolic longitudinal LV strain is either reported as similar ${ }^{24}$ or lower $^{6}{ }^{25}$ in different samples of trained versus untrained participants.

However, mean RV-s' was found to be higher in ATH than in CON, which could imply an adaptation in resting RV longitudinal systolic function following endurance training in females. This may seem logical as the $\mathrm{RV}$ is more dependent on longitudinal shortening than the $\mathrm{LV}^{26}$ and an augmentation in RV longitudinal function in athletes is supported by previous cross-sectional echocardiographic studies using M-mode $^{3} 27$ and TDI. ${ }^{8} 92829$ However, when accounting for increased cardiac length, these differences have been shown to diminish. ${ }^{9}$ Indeed, results are more conflicting from studies measuring RV strain, ${ }^{7} 8$ which has been found unrelated to RV size. ${ }^{30}$ Our results indicate that previous results on increased cardiac longitudinal function must be interpreted with caution, and future studies should either account for cardiac length or apply relative measures of cardiac function.

\section{Segmental LV and RV systolic function}

Peak systolic velocity was higher in ATH than in CON in $\mathrm{RV}$ segments studied as well as in segments adjacent to the RV, while the opposite was seen in the basal LV lateral wall. This could imply that either the free RV wall and septum adapt to endurance training in a similar fashion, possibly augmenting RV longitudinal shortening, or that an adaptation in RV longitudinal function influences septal movement. The septum is an 
important factor in ventricular interdependence, and both circumferential and longitudinal muscle fibres from the RV free wall traverse into the interventricular septum. ${ }^{31}$ Interestingly, training-induced changes in RV dimension and longitudinal systolic function have shown a negative correlation with changes in septal circumferential strain at the mid-ventricular level. ${ }^{32}$ Altogether, there could be a shift from circumferential towards longitudinal shortening in the mid-ventricular septum of endurance athletes. This needs to be confirmed in future studies, ideally in male as well as in female athletes, and the practical implications remain to be elucidated.

There are no available studies describing segmental systolic myocardial function in female athletes. However, there are some conflicting results from studies on predominately male participants examining individual LV segments, most often constrained to basal s' in LV septal and lateral walls. These two measures have been found either concomitantly higher in ATH than in $\mathrm{CON}^{8}{ }^{8} 33$ higher only in septum ${ }^{34} 35$ or concomitantly similar between groups. ${ }^{28} 3637$ In addition, a few studies report segmental strain in the same two segments to be either concomitantly similar, ${ }^{36}$ concomitantly higher ${ }^{37}$ in ATH than in CON or higher in $\mathrm{CON}$ in the basal septum but not in the basal lateral LV wall. ${ }^{38}$ Reports on RV segmental strain are equally conflicting. ${ }^{782836}$

So how does one explain these seemingly inconsistent results in endurance athletes? First, there is a large variation in the athletic populations studied, ranging from rowers ${ }^{8334}$ and cyclists ${ }^{23} 2435$ to soccer players, ${ }^{69} 36$ and thus, training protocols will vary considerably. Cardiac function may also change with increasing age or duration of training. Our results apply to young females. Second, the characteristics of the included control group are of importance when searching for sometimes subtle differences between groups, and an objective measure of the physical conditioning of control participants is not always presented. Third, the methodology used for assessing myocardial function varies, especially for strain imaging, with different vendors and software platforms being used, and what measures and settings to apply is not fully determined. Considering the factors outlined above and with newer echocardiographic techniques continuously evolving, care must be taken in standardisation and validation of measurements, as well as in selection and description of participants in future studies.

There are some relevant limitations of the current study. First, although we report segmental tissue velocity data for both ventricles, our study protocol did not include RV strain measurements, which would be a measure independent of the increased cardiac length of athletes. Second, we chose to omit apical measurements on theoretical grounds-as it is doubtful that adequate longitudinal function measurements can be obtained in these segments-as well as on practical grounds, as these were not obtainable in some subjects. Third, the athletes included participated in a variety of endurance sports, all categorised as having a high-dynamic component according to the Mitchell classification. ${ }^{39}$ The amount of static component in the respective sports included, however, varied. As the study was not powered to allow for comparisons between different sports, the impact of the static component in high-dynamic sports on the female athlete's heart was not addressed in this study. Possibly, this may to some extent explain previously conflicting results from studies investigating cardiac function in endurance athletes. Fourth, this study included exclusively young female endurance athletes, which has implication in generalising the results to older athletes and males. Finally, the inter-rater and intra-rater variability should always be considered. At least for strain measurements, this could in part be attributed to inherent limitations of the software algorithms, where small corrections of the width and placement of the region of interest may have large impact on strain data. This could contribute to the somewhat conflicting results from previous studies.

In conclusion, we found differences in segmental myocardial systolic function between trained and untrained females that imply there are adaptations in cardiac function at rest following endurance training not apparent with global measures of systolic function. As differences in segmental peak systolic velocities were clearly affected by cardiac length, a length-independent measure of systolic function, such as strain, may be preferable in athlete-control studies. Moreover, our finding of similar interventricular and intraventricular synchrony in trained and untrained participants could aid in sports cardiological evaluations.

Twitter Follow Kristofer Hedman at @KristoferHedman

Acknowledgements The authors would like to acknowledge Professor emeritus Jan Henriksson at the department of physiology and pharmacology at Karolinska Institutet, for his help with patient recruitment and scientific considerations and Professor Jan Engvall at the department of clinical physiology at Linköping University hospital for his technical and methodological advice.

Contributors EN was responsible for study design and for performing echocardiography. NB was responsible for the exercise tests. KH performed data collection and measurements, under supervision by EN and ÉT. KH, ÉT, EN and LB were engaged in primary data analysis, while all the authors took part in interpreting and discussing the results. $\mathrm{KH}$ drafted the first version of the manuscript, while ÉT, NB, LB and EN actively engaged in the critical revision for important intellectual content and final preparation of this manuscript. All the authors have approved the final manuscript and $\mathrm{KH}$ is the guarantor.

Funding This research was funded by ALF Grants, County Council of Östergötland, grant number LIO-448101.

Competing interests None declared.

Ethics approval The regional ethical review board in Linköping, Sweden.

Provenance and peer review Not commissioned; externally peer reviewed.

Open Access This is an Open Access article distributed in accordance with the Creative Commons Attribution Non Commercial (CC BY-NC 4.0) license, which permits others to distribute, remix, adapt, build upon this work noncommercially, and license their derivative works on different terms, provided the original work is properly cited and the use is non-commercial. See: http:// creativecommons.org/licenses/by-nc/4.0/ 


\section{REFERENCES}

1. Pelliccia A, Maron BJ, Culasso F, et al. Athlete's heart in women. Echocardiographic characterization of highly trained elite female athletes. JAMA 1996;276:211-15.

2. Whyte GP, George K, Nevill A, et al. Left ventricular morphology and function in female athletes: a meta-analysis. Int $J$ Sports Med 2004;25:380-3.

3. Hedman K, Tamás É, Henriksson J, et al. Female athlete's heart: systolic and diastolic function related to circulatory dimensions. Scand J Med Sci Sports 2015;25:372-81.

4. Utomi V, Oxborough D, Whyte GP, et al. Systematic review and meta-analysis of training mode, imaging modality and body size influences on the morphology and function of the male athlete's heart. Heart 2013;99:1727-33.

5. Pluim BM, Zwinderman AH, van der Laarse A, et al. The athlete's heart. A meta-analysis of cardiac structure and function. Circulation 2000;101:336-44.

6. Richand V, Lafitte $\mathrm{S}$, Reant $\mathrm{P}$, et al. An ultrasound speckle tracking (two-dimensional strain) analysis of myocardial deformation in professional soccer players compared with healthy subjects and hypertrophic cardiomyopathy. Am J Cardiol 2007;100:128-32.

7. Teske AJ, Prakken NH, De Boeck BW, et al. Echocardiographic tissue deformation imaging of right ventricular systolic function in endurance athletes. Eur Heart J 2009;30:969-77.

8. Baggish AL, Yared K, Weiner RB, et al. Differences in cardiac parameters among elite rowers and subelite rowers. Med Sci Sports Exerc 2010;42:1215-20.

9. Pela G, Bruschi G, Montagna L, et al. Left and right ventricular adaptation assessed by Doppler tissue echocardiography in athletes. J Am Soc Echocardiogr 2004;17:205-11.

10. D'Andrea A, Caso P, Cuomo S, et al. Prognostic value of intra-left ventricular electromechanical asynchrony in patients with mild hypertrophic cardiomyopathy compared with power athletes. $\mathrm{Br} \mathrm{J}$ Sports Med 2006;40:244-50.

11. Sahlén A, Shahgaldi K, Aminoff A, et al. Effects of prolonged exercise on left ventricular mechanical synchrony in long-distance runners: importance of previous exposure to endurance races. J Am Soc Echocardiogr 2010;23:977-84.

12. De Castro S, Faletra F, Di Angelantonio E, et al. Tomographic left ventricular volumetric emptying analysis by real-time 3-dimensional echocardiography: influence of left ventricular dysfunction with and without electrical dyssynchrony. Circ Cardiovasc Imaging 2008;1:41-9.

13. Caselli S, Di Paolo FM, Pisicchio C, et al. Three-dimensional echocardiographic characterization of left ventricular remodeling in Olympic athletes. Am J Cardiol 2011;108:141-7.

14. Sadeghian $H$, Ahmadi $F$, Lotfi-Tokaldany $M$, et al. Ventricular asynchrony of time-to-peak systolic velocity in structurally normal heart by tissue Doppler imaging. Echocardiography 2010;27:823-30.

15. Miyazaki C, Powell BD, Bruce CJ, et al. Comparison of echocardiographic dyssynchrony assessment by tissue velocity and strain imaging in subjects with or without systolic dysfunction and with or without left bundle-branch block. Circulation 2008;117:2617-25.

16. Lang RM, Badano LP, Mor-Avi V, et al. Recommendations for cardiac chamber quantification by echocardiography in adults: an update from the American society of echocardiography and the European association of cardiovascular imaging. J Am Soc Echocardiogr 2015;28:1-39 e14.

17. Bader $\mathrm{H}$, Garrigue $\mathrm{S}$, Lafitte $\mathrm{S}$, et al. Intra-left ventricular electromechanical asynchrony. A new independent predictor of severe cardiac events in heart failure patients. J Am Coll Cardiol 2004;43:248-56.

18. $\mathrm{Yu} \mathrm{CM}$, Lin $\mathrm{H}$, Zhang $\mathrm{Q}$, et al. High prevalence of left ventricular systolic and diastolic asynchrony in patients with congestive heart failure and normal QRS duration. Heart 2003;89:54-60.

19. Yu CM, Chau E, Sanderson JE, et al. Tissue Doppler echocardiographic evidence of reverse remodeling and improved synchronicity by simultaneously delaying regional contraction after biventricular pacing therapy in heart failure. Circulation 2002;105:438-45.

20. Dahlberg G. Errors of estimation. In: Dahlberg G, ed. Statistical methods for medical and biological students. 2nd edn. London: George Allen \& Unwin Ltd, 1948:122-32.

21. Brutsaert DL. Nonuniformity: a physiologic modulator of contraction and relaxation of the normal heart. J Am Coll Cardiol 1987:9:341-8.

22. $\mathrm{Ng} \mathrm{AC,} \mathrm{Tran} \mathrm{da} \mathrm{T,} \mathrm{Newman} \mathrm{M,} \mathrm{et} \mathrm{al.} \mathrm{Left} \mathrm{ventricular} \mathrm{longitudinal} \mathrm{and}$ radial synchrony and their determinants in healthy subjects. $J A m$ Soc Echocardiogr 2008;21:1042-8.

23. Poulsen $\mathrm{SH}, \mathrm{Hjortshoj} \mathrm{S}$, Korup $\mathrm{E}$, et al. Strain rate and tissue tracking imaging in quantitation of left ventricular systolic function in endurance and strength athletes. Scand J Med Sci Sports 2007;17:148-55.

24. Nottin S, Doucende G, Schuster-Beck I, et al. Alteration in left ventricular normal and shear strains evaluated by $2 \mathrm{D}$-strain echocardiography in the athlete's heart. J Physiol 2008;586:4721-33.

25. Caselli S, Montesanti D, Autore C, et al. Patterns of left ventricular longitudinal strain and strain rate in Olympic athletes. J Am Soc Echocardiogr 2015;28:245-53.

26. Petitjean C, Rougon N, Cluzel P. Assessment of myocardial function: a review of quantification methods and results using tagged MRI. J Cardiovasc Magn Reson 2005;7:501-16.

27. Carlhall CJ, Lindstrom L, Wranne B, et al. Atrioventricular plane displacement correlates closely to circulatory dimensions but not to ejection fraction in normal young subjects. Clin Physiol 2001;21:621-8.

28. Poh KK, Ton-Nu TT, Neilan TG, et al. Myocardial adaptation and efficiency in response to intensive physical training in elite speedskaters. Int J Cardiol 2008;126:346-51.

29. Koc M, Bozkurt A, Akpinar O, et al. Right and left ventricular adaptation to training determined by conventional echocardiography and tissue Doppler imaging in young endurance athletes. Acta Cardiol 2007;62:13-18.

30. Oxborough D, Sharma S, Shave R, et al. The right ventricle of the endurance athlete: the relationship between morphology and deformation. J Am Soc Echocardiog 2012;25:263-71.

31. Greenbaum RA, Ho SY, Gibson DG, et al. Left ventricular fibre architecture in man. Br Heart $J$ 1981;45:248-63.

32. Baggish $\mathrm{AL}$, Yared $\mathrm{K}$, Wang $\mathrm{F}$, et al. The impact of endurance exercise training on left ventricular systolic mechanics. Am J Physiol Heart Circ Physiol 2008;295:H1109-H16.

33. Mantziari A, Vassilikos VP, Giannakoulas G, et al. Left ventricular function in elite rowers in relation to training-induced structural myocardial adaptation. Scand J Med Sci Sports 2010;20:428-33.

34. Zoncu S, Pelliccia A, Mercuro G. Assessment of regional systolic and diastolic wall motion velocities in highly trained athletes by pulsed wave Doppler tissue imaging. J Am Soc Echocardiogr 2002;15:900-5.

35. Nottin S, Nguyen LD, Terbah M, et al. Long-term endurance training does not prevent the age-related decrease in left ventricula relaxation properties. Acta Physiol Scand 2004;181:209-15.

36. Tumuklu MM, Etikan I, Cinar CS. Left ventricular function in professional football players evaluated by tissue Doppler imaging and strain imaging. Int $J$ Cardiovasc Imaging 2008;24:25-35.

37. Simsek Z, Gundogdu F, Alpaydin S, et al. Analysis of athletes' heart by tissue Doppler and strain/strain rate imaging. Int $J$ Cardiovasc Imaging 2011;27:105-11.

38. Butz T, van Buuren F, Mellwig KP, et al. Two-dimensional strain analysis of the global and regional myocardial function for the differentiation of pathologic and physiologic left ventricular hypertrophy: a study in athletes and in patients with hypertrophic cardiomyopathy. Int J Cardiovasc Imaging 2011;27:91-100.

39. Mitchell JH, Haskell W, Snell $\mathrm{P}$, et al. Task Force 8: classification of sports. J Am Coll Cardiol 2005;45:1364-7. 